\title{
Monogenoidean parasites of freshwater stingrays (Rajiformes: Potamotrygonidae) from the Negro River, Amazon, Brazil: species of Potamotrygonocotyle (Monocotylidae) and Paraheteronchocotyle (Hexabothriidae)
}

\author{
Marcus V. Domingues ${ }^{1,2}$, Norberto C.M. Pancera ${ }^{1}$ and Fernando P.L. Marques ${ }^{1}$ \\ ${ }^{1}$ Laboratório de Helmintologia Evolutiva, Universidade de São Paulo, Instituto de Biociências, Rua do Matão, trav. 14, no. 321, \\ Cidade Universitária, 05508-900 São Paulo, SP, Brazil; \\ ${ }^{2}$ Postdoctoral fellow from the Fundação de Amparo à Pesquisa ao Estado de São Paulo (Proc. FAPESP no. 04/09267-0)
}

Key words: Monogenoidea, Monocotylidae, Hexabothriidae, Potamotrygonocotyle, Paraheteronchocotyle, Potamotrygonidae, taxonomy, Amazon, Negro River, Brazil

\begin{abstract}
Five new species of Potamotrygonocotyle (Monocotylidae) are described and Paraheteronchocotyle amazonense Mayes, Brooks et Thorson, 1981 (Hexabothriidae) is redescribed from monogenoideans collected on the gills of species of Potamotrygonidae from the Negro River, Amazon, Brazil. Potamotrygonocotyle quadracotyle sp. n. and P. umbella sp. n. were found parasitizing an undescribed species of Potamotrygon; Potamotrygonocotyle rarum $\mathrm{sp}$. $\mathrm{n}$. is described from Potamotrygon schroederi; Potamotrygonocotyle rionegrense inhabits Potamotrygon cf. motoro; Potamotrygonocotyle aramasae sp. $\mathrm{n}$. is a parasite of Paratrygon aiereba; and Paraheteronchocotyle amazonense is reported from Potamotrygon orbignyi. The diagnosis of Paraheteronchocotyle is emended, and P. amazonense is redescribed.
\end{abstract}

Recent efforts to uncover the diversity of monogenoidean parasites of potamotrygonids have revealed the existence of a considerable number of derived lineages that have been overlooked for more than two decades, since the first descriptions of two species restricted to Neotropical freshwater stingrays by Mayes et al. (1981) (see Domingues and Marques 2007). As expected, the fauna of monogenoideans inhabiting potamotrygonids is represented by monocotylids and hexabothriids, groups commonly found on marine elasmobranchs, tracing the origin of the hosts, which are presumed to have been derived from a marine ancestor during marine incursions through the Miocene in the northern part of South America (Lovejoy et al. 1998, 2006, Marques 2000).

Although it is evident that the fauna of monogenoideans is somehow related to its marine counterparts, it seems early to address their relationships while we still know very little about the lineages that are now confined to the rivers of South America. Thus far, only six species of monogenoideans have been reported from potamotrygonids, five belonging to Potamotrygonocotyle Mayes, Brooks et Thorson, 1981 (Monocotylidae) and one to the monotypic Paraheteronchocotyle Mayes, Brooks et Thorson, 1981 (Hexabothriidae) (Mayes et al. 1981, Domingues and Marques 2007). Most of the diversity reported to date is found in the southern hydrographic basins of South America (i.e., Paraná / Paraguay / Uruguay), probably because that area has been targeted for monogenoideans from potamotrygonids (Domingues and Marques 2007). However, as we surveyed other river systems in South America we have found that some regions host a parallel diversity of monogenoideans inhabiting potamotrygonids.

Here, we address the fauna of monogenoidean parasites of potamotrygonids from the Negro River by describing five new species of Potamotrygonocotyle (Monocotylidae) and redescribing Paraheteronchocotyle amazonense found in this river. At least 450 species of fishes representing 41 to 46 families have been reported from the Negro River, a river known for its black and acid water and highly endemic fauna of fishes and parasites (Suriano 1985, Boeger and Kritsky 1988, Goulding et al. 1988, Van Every and Kritsky 1992, Kritsky et al. 1996, 1997, 1998, Kritsky and Boeger 2002). Among the large number of fishes reported from the Negro River, we found four nominal species of Potamotrygonidae: Paratrygon aiereba (Müller et Henle, 1841), Potamotrygon motoro (Müller et Henle, 1841), $P$. schroederi Fernández-Yépez, 1957, P. orbignyi (Castelnau, 1855), and at least one new species, which is under description (de Carvalho et al. 2003). Most of these species are also found in the adjacent Orinoco River Basin to which the Negro River is connected through the Cassiquiari (Goulding et al. 1988, Hubert and Renno 2006). Thus, we would not be surprised if the species reported from the Negro River would also be found in the Orinoco Basin. 


\section{MATERIALS AND METHODS}

Specimens of potamotrygonids were collected using spears, gill nets, or long lines from the Negro River, Municipality of Barcelos, Amazonas, Brazil (0॰58'11'S, 6255'13”'W), during January and February 2004. The gills were removed and placed in plastic bags containing heated $\left(\sim 65^{\circ} \mathrm{C}\right) 4 \%$ formaldehyde solution. Unstained helminths were mounted in Hoyer's or Gray \& Wess medium to study sclerotized structures (Humason 1979). Whole mounts of monogenoideans were stained with Gomory's trichrome to determine internal features (Humason 1979). Measurements, all in micrometres, were performed following Mizelle and Klucka (1953), except for the measurements of the hexabothriid sucker sclerite that are represented by (1) length and width of the shaft and (2) length of the point (Fig. 41). The dimensions of organs and other structures represent the greatest measurement in dorsoventral view; lengths of curved or bent structures (anchors, male copulatory organ) represent straight line distances between extreme ends. The average measurements are followed by ranges and number of specimens measured (n) in parentheses. Illustrations were prepared with aid of a drawing tube on an Olympus BX-51 microscope with differential interference contrast optics. Specimens prepared for scanning electron microscopy were post fixed in $1 \%$ osmium tetroxide for 1-2 hours at room temperature, dehydrated in a graded ethanol series, critical point dried and sputter-coated with gold. Type specimens and vouchers were deposited in the Coleção Helmintológica do Instituto Oswaldo Cruz, Rio de Janeiro, RJ, Brazil (CHIOC); Coleção Helmintológica do Museu de Zoologia da Universidade de São Paulo, São Paulo, SP, Brazil (MZUSP); Instituto de Pesquisas da Amazônia (INPA), Manaus, AM, Brazil; the Harold W. Manter Laboratory of Parasitology (HWML), Lincoln, NE, USA; the United States National Parasite Collection (USNPC), Beltsville, MD, USA; and the Institute of Parasitology, Academy of Sciences of the Czech Republic, České Budějovice, Czech Republic (IPCR). The following museum specimens were examined: holotype, Paraheteronchocotyle amazonense (USNPC 77159); 2 paratypes and 1 paratype, Paraheteronchocotyle amazonense (USNPC 77160 and HWML 21391, respectively). Morphological terminology of monocotylids and hexabothriids follows Chisholm et al. (1995) and Boeger and Kritsky (1989), respectively.

\section{DESCRIPTIONS}

Polyonchoinea Bychowsky, 1937

Monocotylidae Taschenberg, 1879

Heterocotylinae Chisholm, Wheeler et BeverleyBurton, 1995

Potamotrygonocotyle Mayes, Brooks et Thorson, 1981

\section{Potamotrygonocotyle quadracotyle sp. n.}

Figs. 1-11

Description (based on 37 specimens): Body fusiform, total length excluding haptor $273(220-380 ; n=$ $11) ; 130(100-180 ; \mathrm{n}=12)$ wide at level of germarium. Tegument smooth. Cephalic lobes poorly developed or absent; 3 pairs of head organs converging to unique pore (Fig. 8); cephalic glands unicellular, posterolateral to pharynx, with rod-shaped secretion. Anteromedial gland not observed. Dispersed pigment granules laterodorsally to pharynx, infrequently absent. Mouth surrounded by sclerotized ridges (Fig. 9). Pharynx elongate ovate, $37(28-48 ; n=12)$ long, $25(n=12)$ wide; oesophagus short; two intestinal caeca, nonconfluent, partially overlapping, lacking diverticula. Haptor subhexagonal, 134 (113-160; $\mathrm{n}=13)$ long, 110 (95-125; $\mathrm{n}$ $=12$ ) wide, with one central and four peripheral loculi (one anterior, two lateral, one posterior) (Fig. 10); septa ventrally surrounded by slightly sinuous sclerotized ridge (Fig. 11). Dorsal surface of haptor with 2 pairs of haptoral accessory structures associated with lateral and posterior peripheral loculi; each dorsal haptoral accessory structure with sclerotized margins. Anterior pair of dorsal haptoral accessory structures bilobate, with well separated lobes; each lobe elongate, posterior pair of dorsal haptoral accessory structures elongate (Fig. 7). Anchors 42 (36-47; $\mathrm{n}=21)$ long, base 23 (20-25; $\mathrm{n}=$ $10)$ wide, with heavy diverging roots, evenly curved shaft and point. Hooks similar, $11(10-14 ; \mathrm{n}=162)$ long, distributed on marginal membrane of haptor, with depressed thumb, shaft with proximal portion dilated and curved point. Male copulatory organ sclerotized, long straight slightly tapered tube, $36(30-44 ; n=6)$ long, distal portion sinuous, aperture terminal; base with small proximal flap. Accessory piece absent. Testis transversally ovate, $32(30-35 ; \mathrm{n}=8)$ long, 57 (43-73; $\mathrm{n}$ $=8$ ) wide; vas deferens not observed; seminal vesicle Cshaped, entering dorsal surface of posterior region of ejaculatory bulb. Ejaculatory bulb muscular, ovate without distinct internal chambers; glands associated with ejaculatory bulb not observed. Germarium tubular, unbranched, looping right intestinal caecum; distal end ascendant; Mehlis' glands not observed. Vagina muscular. Vaginal pore sinistroventral at level of common genital pore; seminal receptacle spherical. Oötype well developed. Vitellaria coextensive with gut, absent in regions of reproductive organs. Egg ovate, 126 (120$133 ; \mathrm{n}=4)$ long, $59(43-65 ; \mathrm{n}=4)$ wide, with short filament; distal end of filament reticulate. For comparative measurements see Table 1.

Holotype, type host, type locality: MZUSP 6367; Potamotrygon sp., Negro River, Municipality of Barcelos, Amazonas, Brazil (058'11'’S, 62 $55^{\prime} 13$ ”'W), 23 January 2005.

O th e r s p e c i m e n s : 36 paratypes; 18 MZUSP 6368a-r, 4 CHIOC 36883a-d, 4 HWML 48537-48540, 5 INPA 508a-e, 4 USNPC 99793, 1 IPCR M-451; Negro River, Municipality of Barcelos, Amazonas, Brazil $\left(0^{\circ} 58^{\prime} 11^{\prime \prime} \mathrm{S}\right.$, $\left.62^{\circ} 55^{\prime} 13^{\prime \prime} \mathrm{W}\right)$, January and February 2005.

Site of infection: Gills.

E t y m o log y: The specific name refers to the presence of four peripheral loculi in the haptor. 

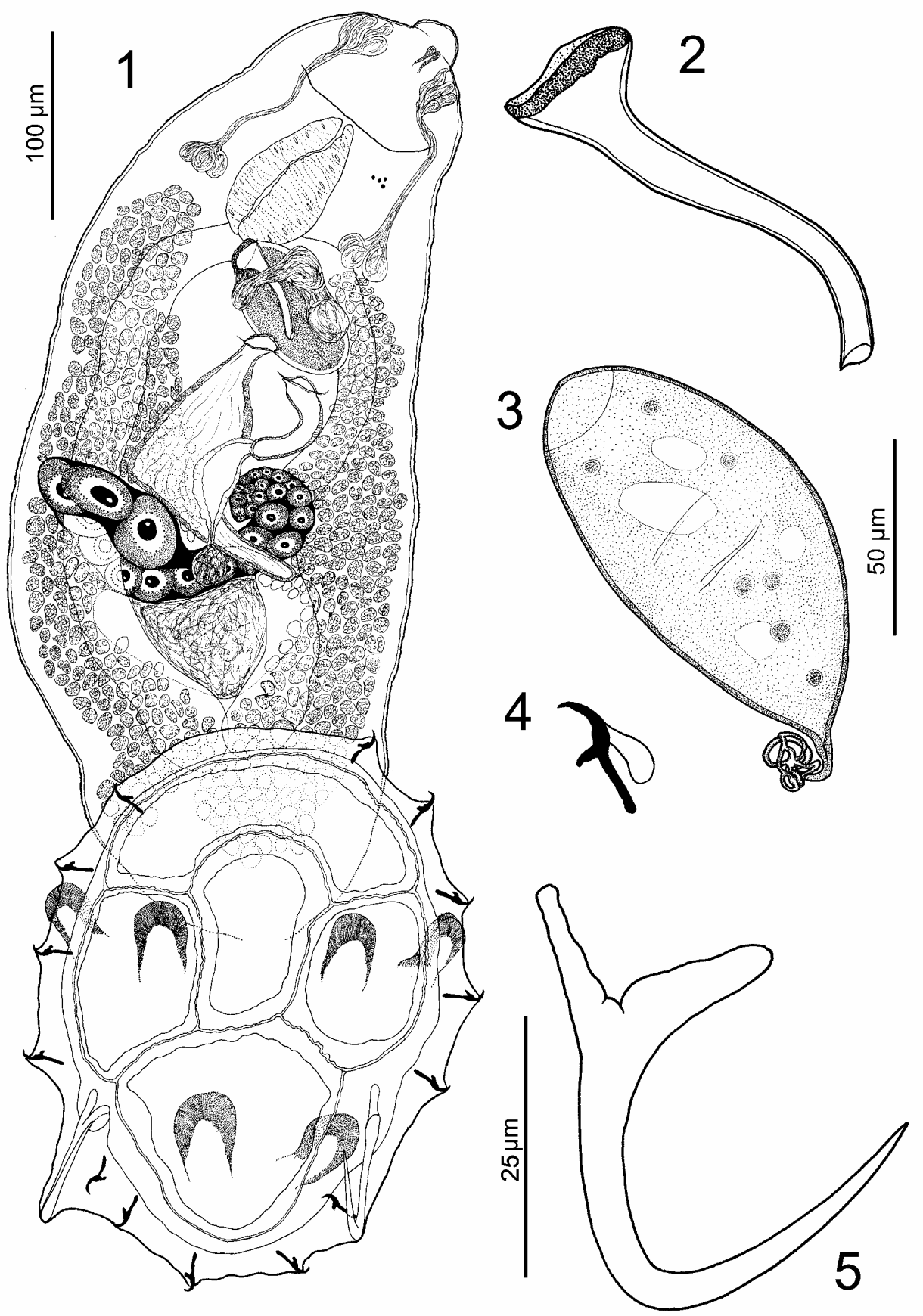

Figs. 1-5. Potamotrygonocotyle quadracotyle sp. n. Fig. 1. Whole mount (holotype). Fig. 2. Male copulatory organ. Fig. 3. Egg. Fig. 4. Hook. Fig. 5. Anchor.

Remarks. Potamotrygonocotyle quadracotyle differs from its congeneric species by having a haptor with one central and four peripheral loculi instead of one central and eight peripheral loculi (Figs. 1, 6, 10). This character is apparently derived within the genus and represents a putative autapomorphy for $P$. quadracotyle. Future discoveries of more species of this genus may justify erection of a separate genus for $P$. quadracotyle based in part on the presence of a haptor with one central and four peripheral loculi.

\section{Potamotrygonocotyle umbella $\mathrm{sp}$. n. Figs. 12-17, 34}

Description (based on 24 specimens): Body fusiform, total length excluding haptor $251(200-300 ; n=$ $14) ; 107(80-130 ; n=14)$ wide; widest at level of germarium. Tegument smooth. Cephalic lobes poorly developed or absent; 3 pairs of head organs converging to unique pore; cephalic glands posterolateral to pharynx. Anteromedial gland not observed. Pigment granules usually absent, infrequently present in cephalic, trunk 

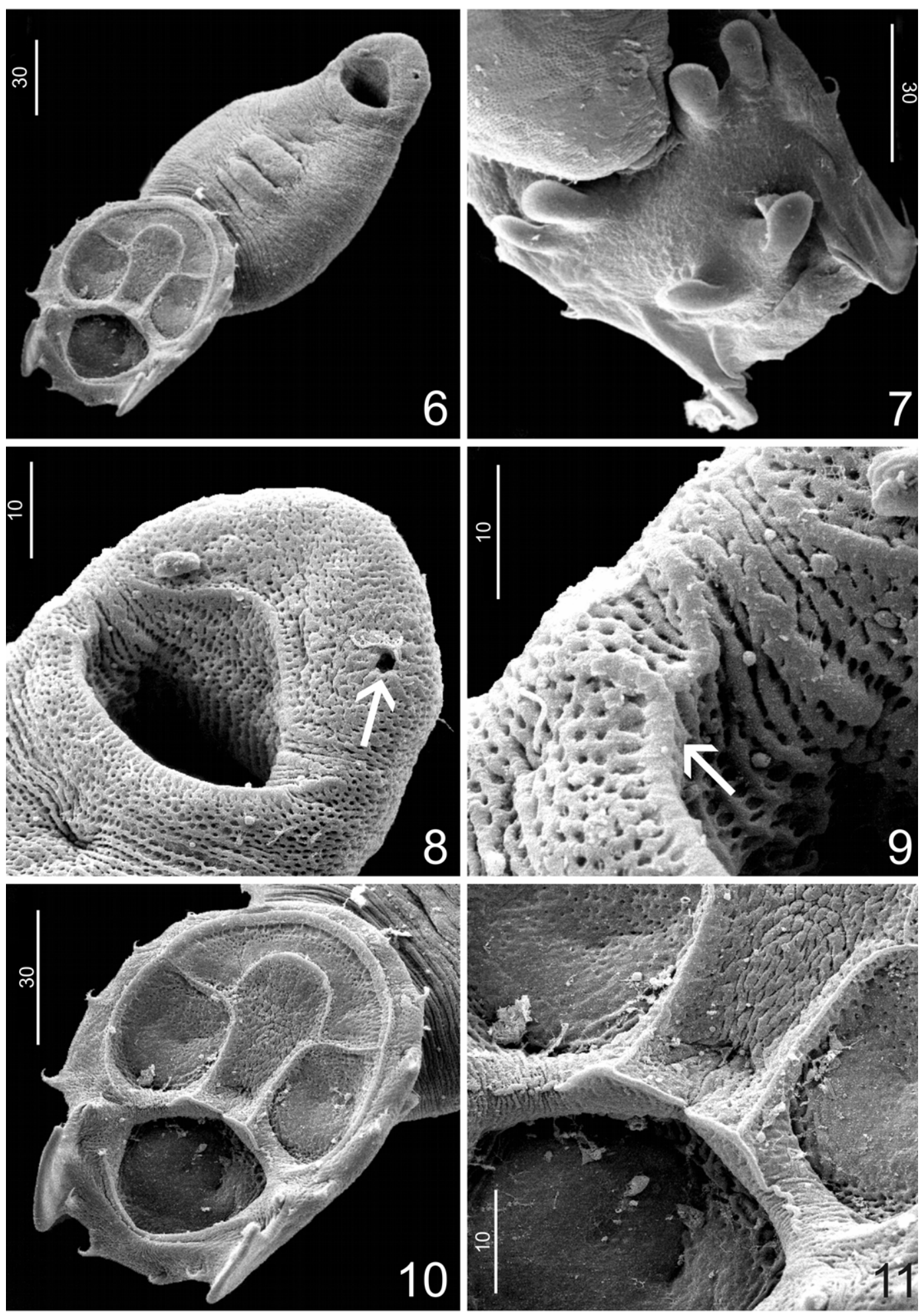

Figs. 6-11. General morphology of structures of Potamotrygonocotyle quadracotyle sp. n., scanning electron micrographs. Fig. 6. Whole specimen ventral view. Fig. 7. General morphology of dorsal haptoral accessory structures. Fig. 8. Detail of anterior region; arrow shows the single pore of head organs opening on left side of the head. Fig. 9. Detail of anterior region; arrow shows the sclerotisation around the mouth. Fig. 10. Ventral view of haptor showing loculi. Fig. 11. Detail of haptoral septa. Scale bars in $\mu \mathrm{m}$. 


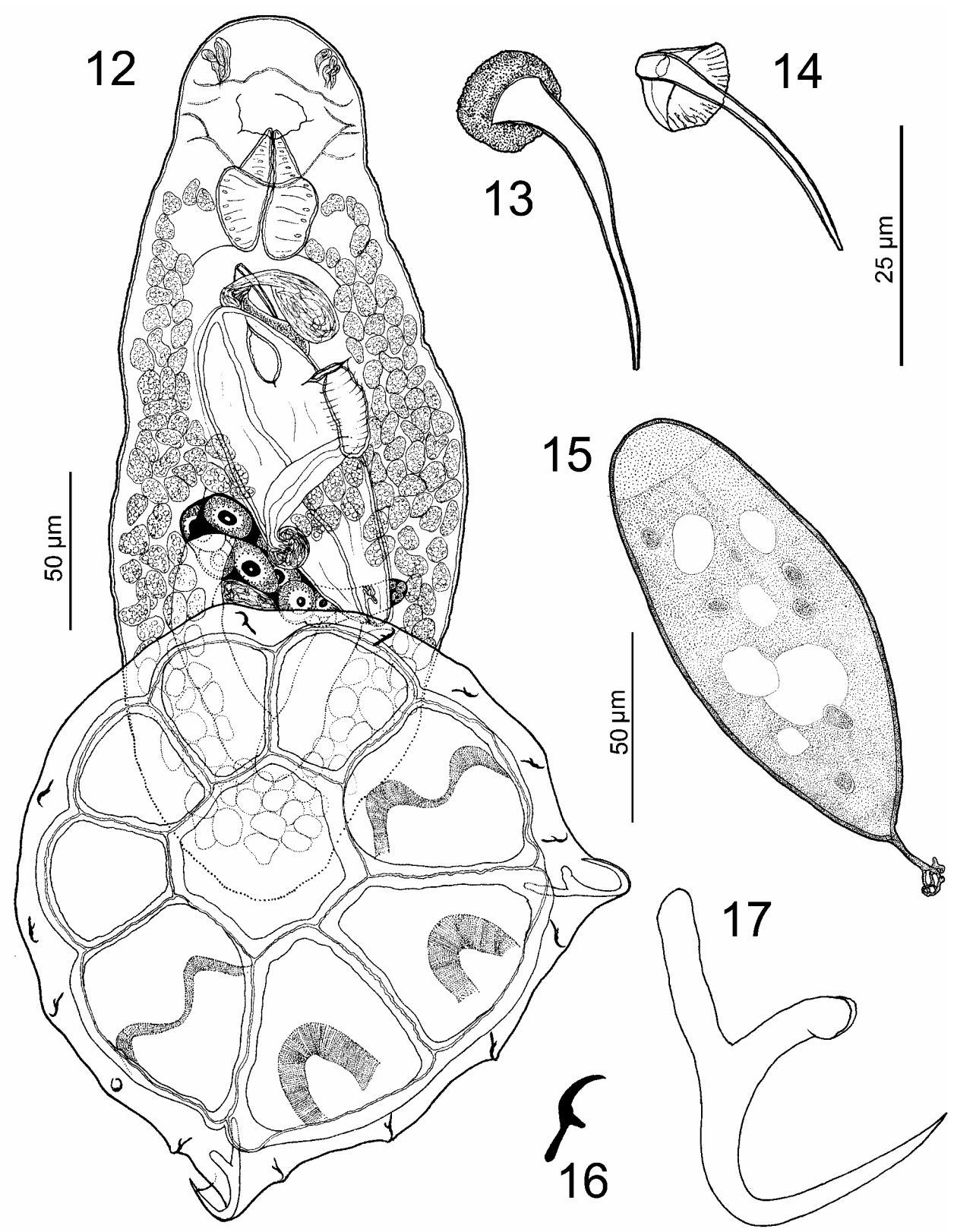

Figs. 12-17. Potamotrygonocotyle umbella sp. n. Fig. 12. Whole mount (composite drawing). Fig. 13. Male copulatory organ. Fig. 14. Male copulatory organ (bent). Fig. 15. Egg. Fig. 16. Hook. Fig. 17. Anchor.

regions. Mouth surrounded by slight sclerotisations. Pharynx elongate ovate, $38(35-40 ; \mathrm{n}=13)$ long, 28 $(25-30 ; n=13)$ wide; oesophagus short; two intestinal caeca, nonconfluent, partially overlapping, lacking diverticula. Haptor circular, haptoral disc approximately $2 / 3$ of body length, $169(155-180 ; n=12)$ long, 169 $(135-190 ; \mathrm{n}=12)$ wide, with one central and eight peripheral loculi (two anterior, four lateral, two posterior); septa ventrally surmounted by slightly sinuous sclerotized ridge. Dorsal pairs of haptoral accessory structures associated with the four posterior peripheral loculi; each pad with sclerotized margins. Anterior pair of dorsal haptoral accessory structures bilobate with divergent rounded lobes, each anterior pad with slightly concave separation between lobes, posterior pair of dorsal haptoral accessory structures elongate (Fig. 34). Anchors 37 (34-39; $\mathrm{n}=12)$ long, base $15(14-17 ; \mathrm{n}=$ $11)$ wide, with heavily diverging roots, evenly curved shaft and point. Hooks similar, $10(8-11 ; \mathrm{n}=36)$ long, distributed on marginal membrane of haptor, with depressed thumb, shaft with proximal portion dilated and curved point. Male copulatory organ sclerotized, arcuate, tapered tube, $36(34-38 ; \mathrm{n}=5)$ long, distal portion acute, aperture terminal. Accessory piece absent. Testis transversal ovate, $41(33-50 ; n=14)$ long, 53 (48-68; $n$ $=13$ ) wide; vas deferens not observed; seminal vesicle sigmoid, entering dorsally at posterior region of ejaculatory bulb. Ejaculatory bulb muscular, ovate without 
distinct internal chambers; glands associated with ejaculatory bulb not observed. Germarium tubular, unbranched, looping right intestinal caecum; distal end transversal to body; Mehlis' glands not observed. Vagina and vaginal canal muscular. Vaginal pore sinistroventral at level of common genital pore; seminal receptacle spherical. Oötype well developed. Vitellaria coextensive with gut, absent in regions of reproductive organs. Egg ovate, $121(110-130 ; n=9)$ long, 49 (43$58 ; \mathrm{n}=8$ ) wide, with short filament; distal end reticulate. For comparative measurements see Table 1.

Holotype, type host, type locality: MZUSP 6369; Potamotrygon sp., Negro River, Municipality of Barcelos, Amazonas, Brazil (058'11'S, 6255’13”W), 23 January 2005.

O t h e r s p e c i m e n s : 23 paratypes; 11 MZUSP 6370a-k, 2 CHIOC 36884a-b, 2 HWML 48541-48542, 5 INPA 509a-e, 2 USNPC 99794, 1 IPCR M-452; Negro River, Municipality of Barcelos, Amazonas, Brazil $\left(0^{\circ} 58^{\prime} 11\right.$ 'S, $62^{\circ} 55^{\prime} 13$ 'W), January and February 2005.

Site of infection: Gills.

E t y m o log y: The specific name is from Latin (umbella $=$ an umbrella) and refers to the morphology of the haptoral disc.

Remarks. Potamotrygonocotyle umbella closely resembles $P$. quadracotyle in comparative morphology of the posterior pair of dorsal haptoral accessory structures. Features distinguishing this species from $P$. quadracotyle and other congeners include presence of an arcuate male copulatory organ, tapered tube with distal acute tip, and a haptoral disc approximately $2 / 3$ of the body length.

Potamotrygonocotyle rarum sp. n. Figs. 18-21, 35

Description (based on 6 specimens): Body fusiform, total length excluding haptor $460(430-490 ; n=2) ; 195$ $(180-210 ; n=2)$ wide; widest at the level of germarium. Tegument smooth. Cephalic lobes poorly developed or absent; 3 pairs of head organs converging to unique pore; cephalic glands posterolateral to pharynx. Anteromedial gland not observed. Dispersed pigment granules laterodorsally to pharynx, infrequently absent. Mouth surrounded by slight sclerotisations. Pharynx elongate ovate, $90(88-93 ; \mathrm{n}=2)$ long, $53(50-55 ; \mathrm{n}=$ 2) wide; oesophagus short; two intestinal caeca, nonconfluent, lacking diverticula. Haptor circular, haptoral disc approximately half of body length, $203(185-220 ; n=2)$ long, $208(195-220 ; \mathrm{n}=2)$ wide, with one central and eight peripheral loculi (two anterior, four lateral, two posterior); septa ventrally surmounted by slightly sinuous sclerotized ridge. Dorsal pairs of haptoral accessory structures associated with lateral and posterior peripheral loculi; each pad with sclerotized margins. Anterior pair of dorsal haptoral accessory structures bilobate, with poorly separated lobes; each lobe semicircular, posterior pair of dorsal haptoral accessory structures semicircular (Fig. 35). Anchors $65(\mathrm{n}=1)$ long, base 27

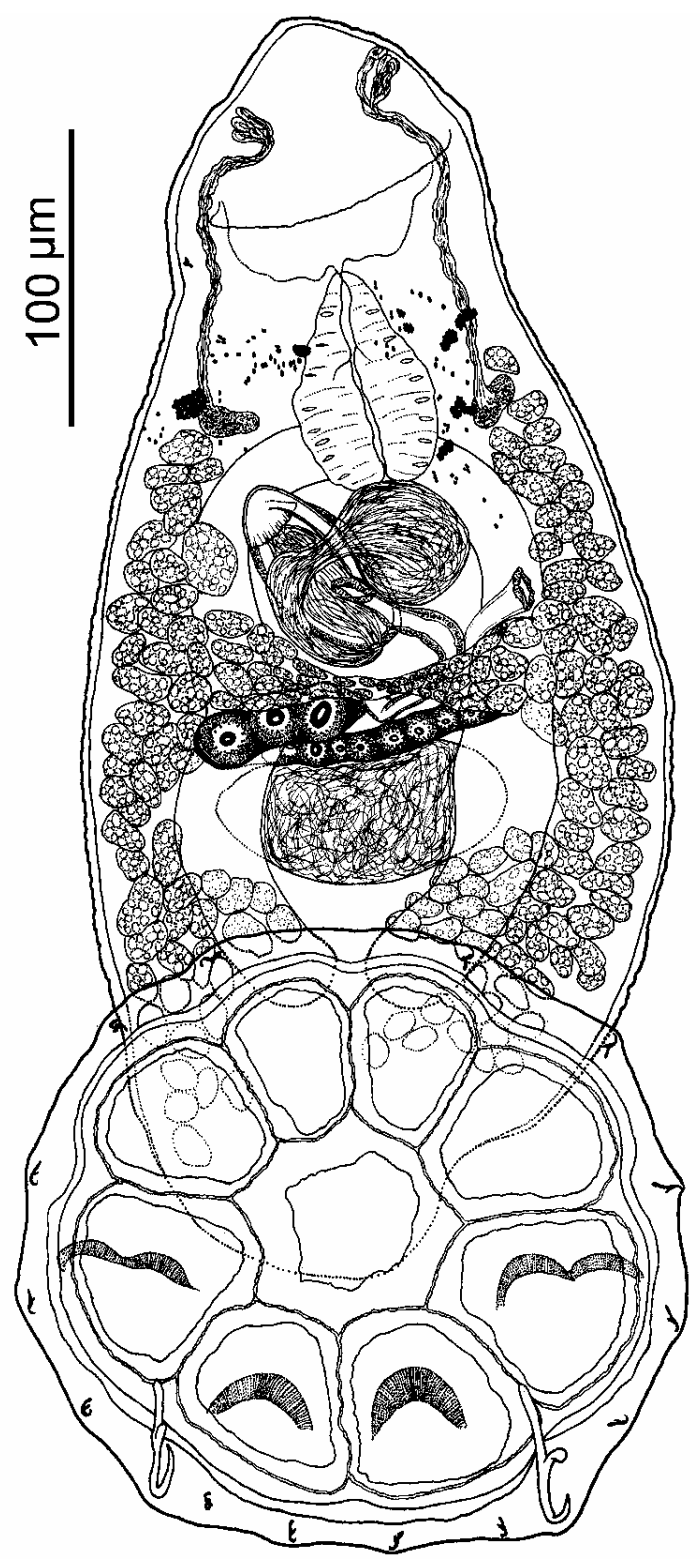

Fig. 18. Potamotrygonocotyle rarum $\mathrm{sp}$. n. Whole mount (holotype).

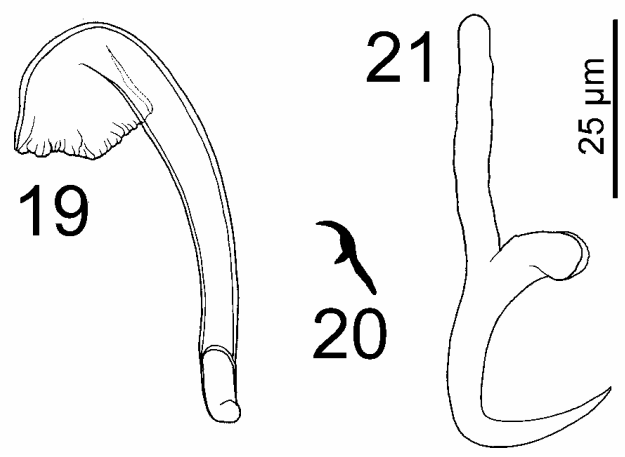

Figs. 19-21. Potamotrygonocotyle rarum sp. n. Fig. 19. Male copulatory organ. Fig. 20. Hook. Fig. 21. Anchor. 

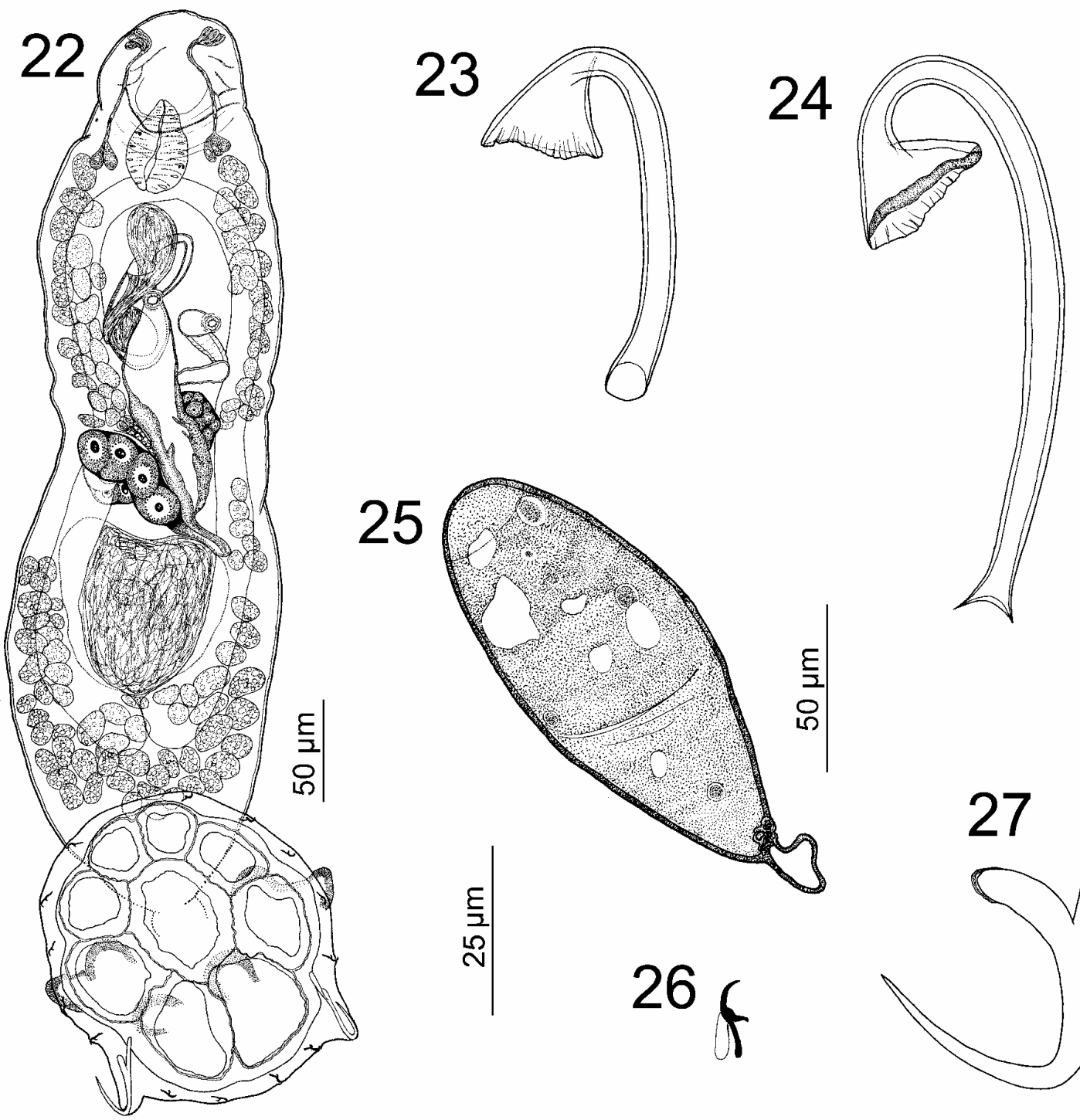

Figs. 22-27. Potamotrygonocotyle rionegrense sp. n. Fig. 22. Whole mount (holotype). Fig. 23. Male copulatory organ. Fig. 24. Male copulatory organ (bent). Fig. 25. Egg. Fig. 26. Hook. Fig. 27. Anchor.

$(\mathrm{n}=1)$ wide, with heavily diverging roots, deep root twice as big as superficial root; evenly curved shaft and point. Hooks similar, $12(10-13 ; \mathrm{n}=12)$ long, distributed on marginal membrane of haptor, with depressed thumb, shaft with dilated proximal portion and curved point. Male copulatory organ sclerotized, arcuate, proximal portion bent dorsally, distal aperture subterminal, $58(51-63 ; n=3)$ long. Accessory piece absent. Testis transversally ovate, $60(53-68 ; \mathrm{n}=2)$ long, 94 $(88-100 ; n=2)$ wide; vas deferens not observed; seminal vesicle $\mathrm{C}$-shaped, entering dorsally at posterior region of ejaculatory bulb. Ejaculatory bulb muscular, ovate with two anterior ovate internal chambers; glands associated with ejaculatory bulb not observed. Germarium tubular, unbranched, looping right intestinal caecum; distal end ascendant; Mehlis' glands not observed. Vagina and vaginal canal muscular. Vaginal pore sinistroventral at level of common genital pore; seminal receptacle not observed. Oötype well devel- oped. Vitellaria coextensive with gut, absent in the regions of reproductive organs. Egg not observed. For comparative measurements see Table 1.

Holotype, type host, type locality: MZUSP 6371; Potamotrygon schroederi Fernández-Yépez, 1958, Negro River, Municipality of Barcelos, Amazonas, Brazil $\left(0^{\circ} 58^{\prime} 11^{\prime \prime} \mathrm{S}, 62^{\circ} 55^{\prime} 13^{\prime \prime} \mathrm{W}\right), 25$ January 2004.

O the r s p e c i m e n s : 5 paratypes; 4 MZUSP 6372a-d, 1 IPCR M-453; Negro River, Municipality of Barcelos, Amazonas, Brazil (058'11'S, 62 55'13”W), January and February 2005.

Site of infection: Gills.

E t y m o lo g y : The specific name is from Latin (rarum = rare) and it refers to the fact that only a few specimens were collected from 13 host specimens in the Negro River, January and February 2005.

Remarks. Potamotrygonocotyle rarum resembles $P$. tsalickisi Mayes, Brooks et Thorson, 1981 by having an ejaculatory bulb with two anterior internal chambers 


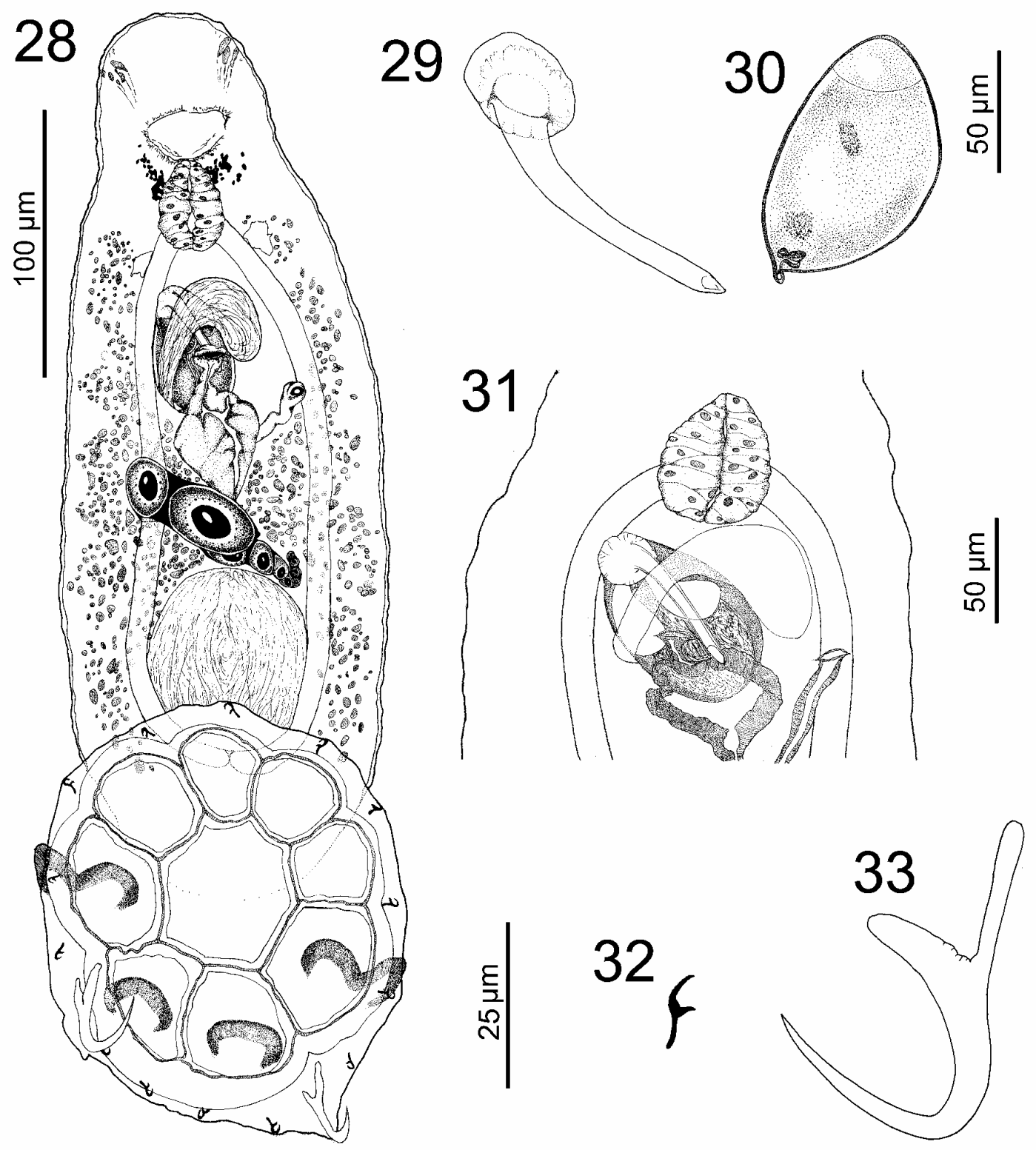

Figs. 28-33. Potamotrygonocotyle aramasae sp. n. Fig. 28. Whole mount (composite drawing). Fig. 29. Male copulatory organ. Fig. 30. Egg. Fig. 31. Detail of reproductive structures. Fig. 32. Hook. Fig. 33. Anchor.

and in the general morphology of the male copulatory organ. However, it differs from P. tsalickisi by having anchors with deep roots twice as long as the superficial roots.

\section{Potamotrygonocotyle rionegrense sp. $\mathrm{n}$.}

Figs. 22-27, 36

Description (based on 42 specimens): Body fusiform, with constriction at midlength, total length excluding haptor $356(300-480 ; \mathrm{n}=11) ; 142(140-205 ; \mathrm{n}$ $=11$ ) wide; greatest width usually in posterior trunk. Tegument smooth. Cephalic lobes poorly developed or absent; 3 pairs of head organs converging to unique pore; cephalic glands posterolateral to pharynx. Anteromedial gland not observed. Pigment granules usu- ally absent, infrequently in cephalic, trunk regions. Mouth surrounded by slight sclerotisations. Pharynx elongate ovate, $49(43-58 ; \mathrm{n}=9)$ long, $32(25-38 ; \mathrm{n}=$ 9) wide; oesophagus short; two intestinal caeca, nonconfluent, partially overlapping, lacking diverticula. Haptor circular, 171 (140-205; $\mathrm{n}=9)$ ) long, 169 (135-200; $\mathrm{n}=$ 9) wide, with one central and eight peripheral loculi (two anterior, four lateral, two posterior); septa ventrally surmounted by slightly sinuous sclerotized ridge. Dorsal pairs of haptoral accessory structures associated with lateral and posterior peripheral loculi; each pad with sclerotized margins. Anterior pair of dorsal haptoral accessory structures bilobate, with well separated lobes, each lobe circular; posterior pair of dorsal haptoral accessory structures circular (Fig. 36). Anchors 46 (42- 

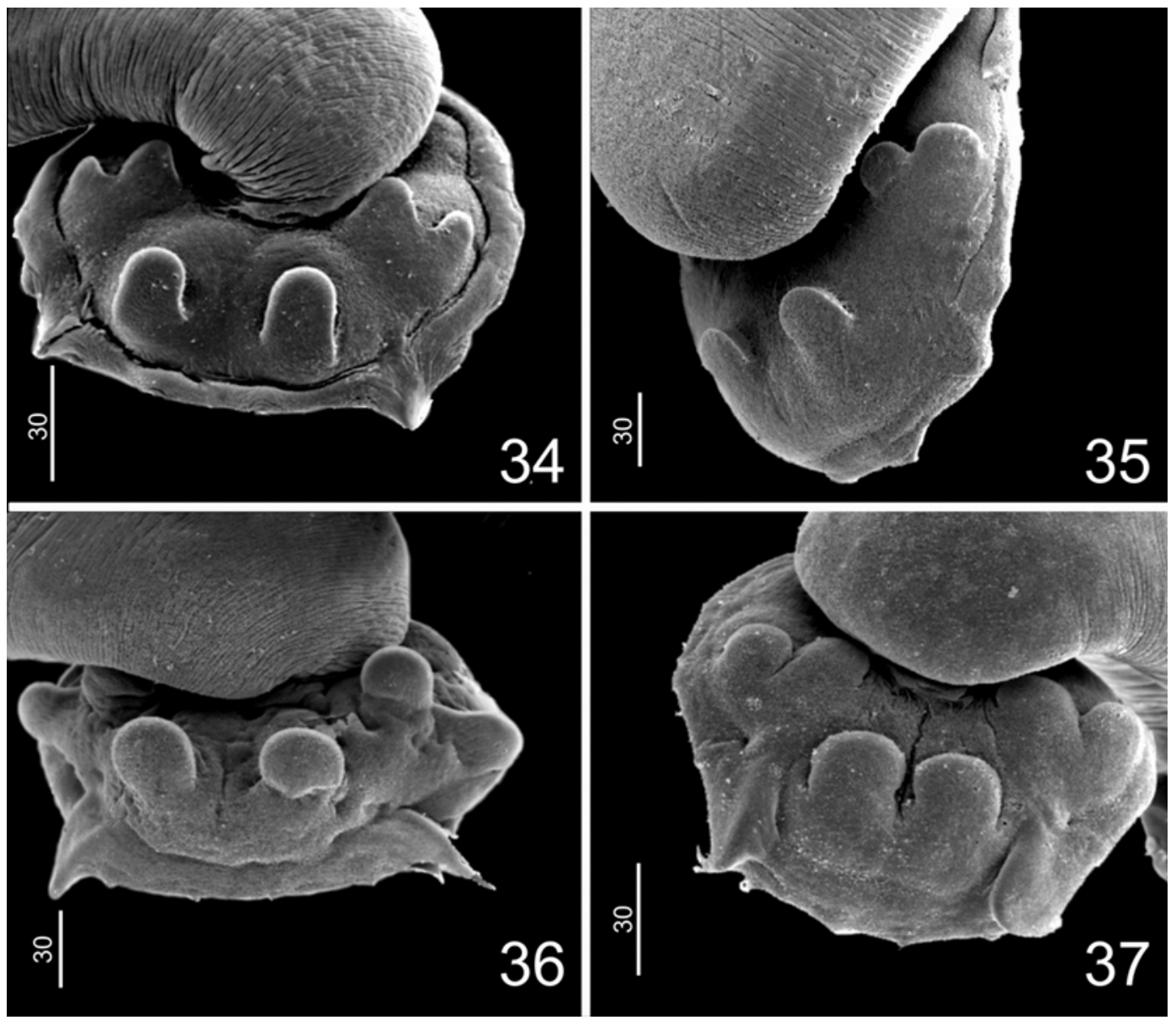

Figs. 34-37. General morphology of dorsal haptoral accessory structures of Potamotrygonocotyle spp., scanning electron micrographs. Fig. 34. Potamotrygonocotyle umbella sp. n. Fig. 35. Potamotrygonocotyle rarum sp. n. Fig. 36. Potamotrygonocotyle rionegrense sp. n. Fig. 37. Potamotrygonocotyle aramasae sp. n. Scale bars in $\mu \mathrm{m}$.

$51 ; \mathrm{n}=23)$ long, base $21(18-24 ; \mathrm{n}=17)$ wide, with heavily diverging roots, evenly curved shaft and point. Hooks similar, $12(10-13 ; \mathrm{n}=116)$ long, distributed on marginal membrane of haptor, with depressed thumb, shaft with dilated proximal portion and curved point. Male copulatory organ sclerotized, arcuate, 70 (58-92; $\mathrm{n}=21$ ) long, proximal portion bent dorsally, directed posteriorly; distal aperture terminal, concave; base with small proximal flap. Accessory piece absent. Testis transversally ovate, $60(50-80 ; \mathrm{n}=10)$ long, 80 (68-98; $\mathrm{n}=10$ ) wide; vas deferens not observed; seminal vesicle sigmoid, entering dorsally at posterior region of ejaculatory bulb. Ejaculatory bulb muscular, ovate without distinct internal chambers; glands associated with ejaculatory bulb not observed. Germarium tubular, unbranched, looping right intestinal caecum; distal end ascendant; Mehlis' glands not observed. Vagina and vaginal canal muscular. Vaginal pore sinistroventral at level of common genital pore; seminal receptacle spherical. Oötype well developed. Vitellaria coextensive with gut, absent in the regions of reproductive organs and near body midlength. Egg ovate, $110(\mathrm{n}=1)$ long, $40(\mathrm{n}=1)$ wide, with short filament; distal end reticulate. For comparative measurements see Table 1.

Holotype, type host, type locality: MZUSP 6373; Potamotrygon sp., Negro River, Municipality of Barcelos, Amazonas, Brazil (0॰58’11’'S, 62 ${ }^{\circ} 55^{\prime} 13^{\prime}$ 'W), 21 January 2005.

O the r s p e c i m e n s : 41 paratypes; 21 MZUSP 6374a-u, 4 CHIOC 36885a-d, 4 HWML 48543-48546, 5 INPA 503a-e, 6 USNPC 99795-99797, 1 IPCR M-454; Negro River, Municipality of Barcelos, Amazonas, Brazil (058'11'S, 6255'13”'W), January and February 2005.

Site of infection: Gills.

E t y m o log y: The specific name refers to the Negro River, from where the type host was collected.

Remarks. Potamotrygonocotyle rionegrense differs from all other species of the genus by having a sclerotized arcuate male copulatory organ with the proximal portion bent dorsally and then directed posteriorly and by the terminal, concave distal aperture. 
Potamotrygonocotyle aramasae sp. n.

Figs. 28-33, 37

Description (based on 28 specimens): Body fusiform, total length excluding haptor $255(170-360 ; \mathrm{n}=$ $15)$; $136(100-180 ; n=14)$ wide; greatest width usually at level of germarium. Tegument smooth. Cephalic lobes absent; 3 pairs of head organs converging to unique pore; cephalic glands posterolateral to pharynx. Anteromedial gland not observed. Dispersed pigment granules laterodorsally to pharynx, infrequently absent. Mouth surrounded by slight sclerotisations. Pharynx elongate ovate, $50(38-65 ; \mathrm{n}=11)$ long, $30(25-38 ; \mathrm{n}=$ 11) wide; oesophagus short; two intestinal caeca, nonconfluent, lacking diverticula. Haptor subcircular, 165 (130-180; $\mathrm{n}=15)$ long, 148 (115-170; $\mathrm{n}=13)$ wide, with one central and eight peripheral loculi (two anterior, four lateral, two posterior); septa ventrally surmounted by slightly sinuous sclerotized ridge. Dorsal pairs of haptoral accessory structures associated with lateral and posterior peripheral loculi; each pad with sclerotized margins. Anterior pair of dorsal haptoral accessory structures bilobate, with well separated lobes, each lobe semicircular; posterior pair of dorsal haptoral accessory structures ovate (Fig. 37). Anchors 50 (48$53 ; \mathrm{n}=15)$ long, base $19(17-25 ; \mathrm{n}=10)$ wide, with heavily diverging roots and evenly curved shaft and point. Hooks similar, $10(10-11 ; n=89)$ long, distributed on marginal membrane of haptor, with depressed thumb, shaft with dilated proximal portion and curved point. Male copulatory organ sclerotized, arcuate, 54 (47-60; $n=14)$ long, with conical expanded base, acute distal portion, directed posteriorly; distal aperture subterminal. Accessory piece absent. Testis elongate ovate, $72(58-90 ; \mathrm{n}=9)$ long, $58(38-73 ; \mathrm{n}=8)$ wide; vas deferens not observed; seminal vesicle sigmoid, entering dorsally at posterior region of ejaculatory bulb. Ejaculatory bulb muscular, ovate with two anterior ovate internal chambers (Fig. 31); glands associated with ejaculatory bulb not observed. Germarium tubular, unbranched, looping right intestinal caecum; distal end ascendant; Mehlis' glands not observed. Vagina and vaginal canal muscular. Vaginal pore sinistroventral at level of common genital pore; seminal receptacle spherical. Oötype well developed. Vitellaria coextensive with gut, absent in regions of reproductive organs. Egg ovate, $88(\mathrm{n}=1)$ long, $53(\mathrm{n}=1)$ wide, with short filament; distal end reticulate. For comparative measurements see Table 1 .

Holotype, type host, type locality: MZUSP 6375; Paratrygon aiereba, Negro River, Municipality of Barcelos, Amazonas, Brazil (058'11's, $\left.62^{\circ} 55^{\prime} 13^{\prime \prime} \mathrm{W}\right), 26$ January 2005.

O t h e r s p e c i m e n s : 27 paratypes; 11 MZUSP 6376a-k, 4 CHIOC 36886-36887a-c, 2 HWML 48547-48548, 5 INPA 504ab-507, 4 USNPC 99798-99800, 1 IPCR M-455; Negro River, Municipality of Barcelos, Amazonas, Brazil (058'11”S, 62 55'13”W), January and February 2005.

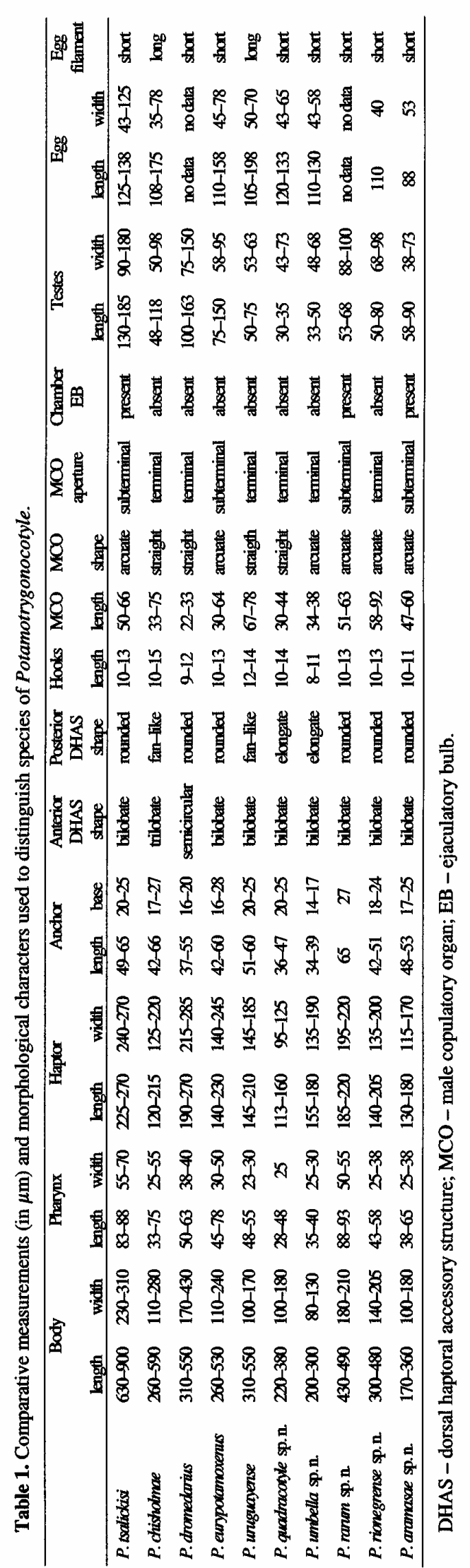


Site of infection: Gills.

E t y m o log y: The specific epithet refers to the local common name of the host, "aramaçã".

Remarks. Potamotrygonocotyle aramasae differs from its congeneric species by having a male copulatory organ with an acute distal tip, a subterminal aperture, and an ejaculatory bulb with two anterior ovate cavities.

Hexabothriidae Price, 1942

Paraheteronchocotyle Mayes, Brooks et Thorson, 1981

Emended diagnosis. Body elongate, comprising oral region, trunk, peduncle and haptor. Tegument thin, smooth. Eyes absent. Mouth subterminal, pharynx muscular, glandular; two intestinal caeca with diverticula, caeca confluent in peduncle posterior to testes, branching into haptor, haptoral appendix. Haptor asymmetrical, sucker complexes linear except complex 1 adjacent to base of haptoral appendix; sucker sclerite 1, 1' similar; haptoral appendix marginal, originating from dorsal haptoral surface lateral to body midline, armed with 0 or 1 anchor, 2 terminal suckers. Cirrus unarmed, comprising two portions: distal part elongate, bulbous; proximal part non-dilated; prostatic region not observed. Testes numerous, irregular; vas deferens sinuous, dorsal to vitelline commissure, with small looping proximal to entrance into cirrus, delicate distal wall of vas deferens. Genital pore at level of gut bifurcation. Germarium lobate anteriorly, sinuous descending germarium branch; ascending germarium branch absent, seminal receptacle not observed; oviduct originating from posterior end of germarium; oötype smooth; uterus lateral to germarium, dorsal to vitellinic channel. Vagina parallel, comprising two segments; distal portion glandular, proximal portion delicate. Vaginal pores on ventral surface about midway between body midline and lateral margin on each side of cirrus. Vitellaria comprising two bilateral bands extending from level of vaginal pores into level of posterior testes; vitelline commissure lateral to germarium, genitointestinal canal dorsal to germarium. Eggs with one polar filament. Parasites of Potamotrygonidae. Type species: Paraheteronchocotyle amazonense Mayes, Brooks et Thorson, 1981.

Remarks. Paraheteronchocotyle was erected by Mayes et al. (1981) to accommodate P. amazonense collected from the freshwater stingray Potamotrygon constellata from the upper Amazon River. The diagnostic characters used to define Paraheteronchocotyle included the uniform-sized suckers, unequal-sized sucker sclerites, and haptoral appendix without anchors. Examination of the type material from USNPC and HWML confirmed the diagnostic features used by Mayes et al. (1981) to recognize $P$. amazonense. The comparison of the type material and voucher specimens collected during the present study suggested that these specimens are conspecific. However, upon study of the voucher specimens, we were able to detect that some
Table 2. Comparative measurements (in $\mu \mathrm{m}$ ) of specimens of Paraheteronchocotyle amazonense from Potamotrygon constellata and P. orbignyi.

\begin{tabular}{|c|c|c|c|c|}
\hline & $\begin{array}{l}\text { Potamotrygon } \\
\text { constellata }\end{array}$ & $\mathrm{n}$ & $\begin{array}{l}\text { Potamotrygon } \\
\text { orbignyi }\end{array}$ & $\mathrm{n}$ \\
\hline \multicolumn{5}{|l|}{ Body } \\
\hline length & $1732(1615-1881)$ & 3 & $1450(1200-1600)$ & 6 \\
\hline width & $483(437-510)$ & 3 & $208(160-240)$ & 6 \\
\hline \multicolumn{5}{|l|}{ Haptor } \\
\hline length & $410(350-446)$ & 3 & $314(280-350)$ & 7 \\
\hline width & $1022(919-1098)$ & 3 & $777(710-850)$ & 7 \\
\hline \multicolumn{5}{|l|}{ Appendix } \\
\hline length & $177(150-203)$ & 2 & $138(120-150)$ & 5 \\
\hline width & $194(188-200)$ & 2 & $138(110-160)$ & 6 \\
\hline \multicolumn{5}{|l|}{ Appendix sucker } \\
\hline length & $109(88-131)$ & 2 & $69(50-95)$ & 6 \\
\hline width & $70(56-85)$ & 2 & $40(30-50)$ & 6 \\
\hline \multicolumn{5}{|l|}{ Oral sucker } \\
\hline length & $88(75-100)$ & 2 & $100(88-108)$ & 6 \\
\hline width & $146(113-180)$ & 2 & $94(88-100)$ & 6 \\
\hline \multicolumn{5}{|l|}{ Pharynx } \\
\hline length & $82(78-87)$ & 2 & $78(63-95)$ & 6 \\
\hline width & $77(76-78)$ & 2 & $63(53-70)$ & 6 \\
\hline \multicolumn{5}{|l|}{ Copulatory organ } \\
\hline length & $96(88-105)$ & 2 & $118(105-125)$ & 3 \\
\hline width & $33(28-38)$ & 2 & $34(30-38)$ & 3 \\
\hline \multicolumn{5}{|l|}{ Testes field } \\
\hline length & - & - & 550 & 1 \\
\hline width & - & - & $85(80-90)$ & 2 \\
\hline \multicolumn{5}{|l|}{ Germarium } \\
\hline length & 606 & 1 & $91(75-100)$ & 4 \\
\hline width & 144 & 1 & $14(13-15)$ & 4 \\
\hline \multicolumn{5}{|l|}{ Egg } \\
\hline length & 141 & 1 & $99(88-115)$ & 3 \\
\hline width & 58 & 1 & 38 & 3 \\
\hline \multicolumn{5}{|l|}{ Anchor } \\
\hline length & - & - & $56(50-63)$ & 3 \\
\hline base width & - & - & $26(25-28)$ & 2 \\
\hline \multicolumn{5}{|l|}{ Sucker sclerite 1} \\
\hline length & $243(234-253)$ & 3 & $153(123-170)$ & 7 \\
\hline width & $34(32-36)$ & 3 & $20(17-22)$ & 7 \\
\hline point length & $95(78-105)$ & 3 & $72(64-78)$ & 7 \\
\hline \multicolumn{5}{|l|}{ Sucker sclerite 2} \\
\hline length & $270(261-277)$ & 5 & $182(157-204)$ & 7 \\
\hline width & $37(32-42)$ & 5 & $27(20-32)$ & 7 \\
\hline point length & $100(88-110)$ & 5 & $79(74-85)$ & 7 \\
\hline \multicolumn{5}{|l|}{ Sucker sclerite 3} \\
\hline length & 199 (181-222) & 4 & $140(131-151)$ & 7 \\
\hline width & $21(20-22)$ & 4 & $16(13-20)$ & 7 \\
\hline point length & $41(37-47)$ & 3 & $45(32-57)$ & 7 \\
\hline \multicolumn{5}{|l|}{ Sucker sclerite 1', } \\
\hline length & $273(251-287)$ & 4 & $186(170-208)$ & 7 \\
\hline width & $37(33-42)$ & 4 & $25(20-29)$ & 7 \\
\hline point length & $101(100-101)$ & 3 & $75(70-79)$ & 7 \\
\hline \multicolumn{5}{|l|}{ Sucker sclerite 2' } \\
\hline length & 213 (199-234) & 3 & $154(140-167)$ & 7 \\
\hline width & $23(22-26)$ & 3 & $17(15-19)$ & 7 \\
\hline point length & $46(43-48)$ & 2 & $40(22-54)$ & 7 \\
\hline \multicolumn{5}{|l|}{ Sucker sclerite 3 , } \\
\hline length & 205 (193-227) & 3 & $147(138-157)$ & 7 \\
\hline width & $22(16-30)$ & 3 & $16(14-20)$ & 7 \\
\hline point length & 26 & 1 & $43(31-53)$ & 7 \\
\hline
\end{tabular}

specimens have anchors (usually one) associated with the haptoral appendix, suggesting that the absence of haptoral anchors may be related to secondary loss as already reported within many groups of Monogenoidea (for discussion see Kritsky and Boeger 1989, Desdevises 2001). In addition, we noticed that Mayes et al. 


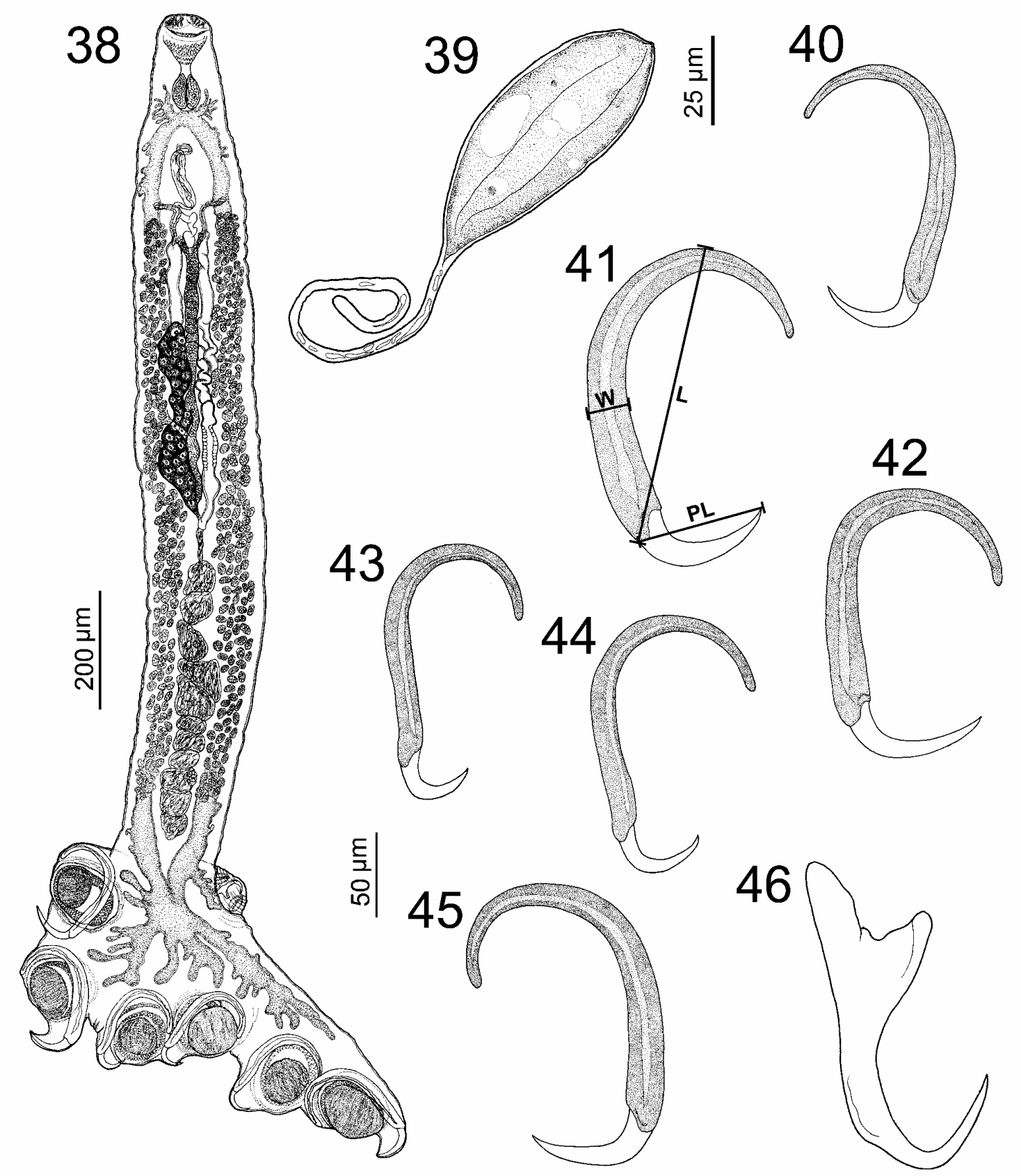

Figs. 38-46. Paraheteronchocotyle amazonense Mayes, Brooks et Thorson, 1981. Fig. 38. Whole mount (composite drawing). Fig. 39. Egg. Fig. 40. Sucker sclerite 1. Fig. 41. Sucker sclerite 2. Fig. 42. Sucker sclerite 3. Fig. 43. Sucker sclerite 1'. Fig. 44. Sucker sclerite 2'. Fig. 45. Sucker sclerite 3'. Fig. 46. Haptoral appendix anchor. L - sucker sclerite length; PL - point length; $\mathrm{W}$ - sucker sclerite width.

(1981) misinterpreted the relative position of testes in the diagnosis of Paraheteronchocotyle. According to them, in Paraheteronchocotyle species the testes were pre-ovarian (= pre-germarian), but examination of the type material and voucher specimens revealed that the testes are postgermarian in the genus.

Boeger and Kritsky (1989) suggested in their cladistic analysis that Paraheteronchocotyle is closely related to Heteronchocotyle based on the morphology of the haptor (sucker complexes linear except complex 1 adjacent to base of haptoral appendix and complex sclerites dissimilar in shape and size). Paraheteronchocotyle differs from Heteronchocotyle by similar sucker sclerites 1, 1' (sclerite 1 dissimilar from 1' in Heteronchocotyle) and eggs with one elongate polar filament (eggs with two flat, elongate polar filaments in Heteronchocotyle). However, their cladistic analysis has many missing data for Paraheteronchocotyle due to the poor conditions of the material used for analysis, suggesting that a new analysis should readdress the phylogenetic position of the genus considering the complete coding for this taxon. 

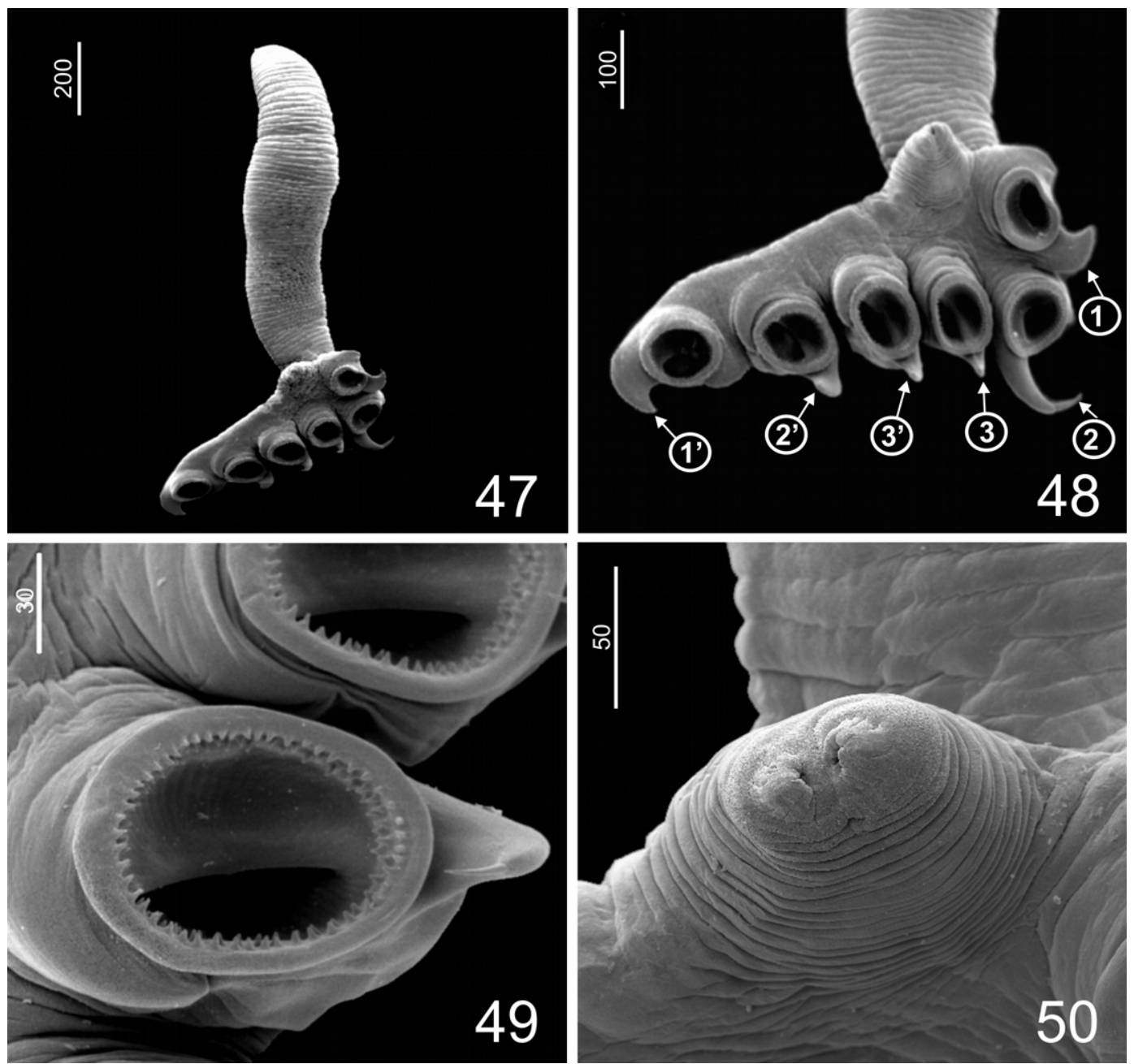

Figs. 47-50. General morphology of structures of Paraheteronchocotyle amazonense Mayes, Brooks et Thorson, 1981, scanning electron micrographs. Fig. 47. Whole specimen (dorsal view). Fig. 48. Detail of haptor. Fig. 49. Detail of haptoral sucker. Fig. 50. Detail of haptoral appendix. Circled numbers identify sucker sclerites in the haptor. Scale bars in $\mu \mathrm{m}$.

Paraheteronchocotyle amazonense Mayes, Brooks et Thorson, 1981

Figs. 38-50

Redescription (based on the holotype, USNPC 77159, 3 paratypes, USNPC 77160 and HWML 21391, and 8 newly collected specimens - see below): Body elongate. Tegument with annulations throughout trunk. Oral sucker with papillae on inner wall; pharynx ovate elongate; intestinal caeca with anterior diverticula lateral to pharynx. Haptor asymmetrical with 3 pairs of equal-sized suckers armed with unequal-sized sucker sclerites and dorsal haptoral appendix. Papillae present on inner wall of haptoral suckers (Fig. 46). Haptoral appendix bearing two terminal, unarmed suckers (Fig. 47). Single anchor when present with wide base, short roots, medially curved shaft and short point. Testes 10 12 in number. Common genital aperture nonpapillate. Egg ovate elongate, polar filament same size as egg; 150 eggs recorded per specimen. For comparative measurements see Table 2 .
T y p e ho s t: Potamotrygon constellata (Vaillant, 1880) $(=P$. circularis $)$.

T y p e 1 o c a 1 i t y: Itacoaí River, $5 \mathrm{~km} \mathrm{SE}$ of Atalaia do Norte, Brazil (July 1976 and July 1978).

Site of infection: Gills.

$\mathrm{N}$ e w 1 y c o 11 e c t e d s p e c i m e n s : 8 vouchers; 4 MZUSP 6377a-d, 1 CHIOC 36888, 1 INPA 510, 1 USNPC 99801, 1 IPCR M-456; Potamotrygon orbignyi (Castelnau, 1855), Negro River, Municipality of Barcelos, Amazonas, Brazil (0 $\left.0^{\circ} 58^{\prime} 11^{\prime \prime S}, 62^{\circ} 55^{\prime} 13^{\prime \prime} \mathrm{W}\right)$, January and February 2005.

Remarks. The examination of the specimens of Paraheteronchocotyle collected from the gills of Potamotrygon orbignyi from the Negro River and type specimens of $P$. amazonense from the gills of $P$. constellata indicates that they are conspecific. Except for the presence of anchors (see generic diagnosis) and some morphometric differences (Table 2), they share similar morphology of the haptoral and reproductive structures. 
The intraspecific morphometric variation detected in specimens of $P$. amazonense collected from different localities and hosts does not support the proposal of a new species of Paraheteronchocotyle. Among ectoparasitic monogenoideans, fluctuations of abiotic (e.g. salinity, temperature) and biotic (e.g. host size) conditions have been shown to influence morphometric variation observed in some haptoral structures (Boeger and Kritsky 1988, Thoney 1988, Mo 1991, Rohde 1991, Perera 1992).

\section{REFERENCES}

Boeger W.A., KRITSKY D.C. 1988: Neotropical Monogenea. 12 Dactylogyridae from Serrasalmus nattereri (Cypriniformes, Serrasalmidae) and aspects of their morphologic variation and distribution in the Brazilian Amazon. Proc. Helminthol. Soc. Wash. 55: 189-213.

BOEGER W.A, KRITSKY D.C. 1989: Phylogeny, coevolution, and revision of the Hexabothriidae Price, 1942 (Monogenea). Int. J. Parasitol. 19: 425-440.

Chisholm L.A., WheEler T.A., BeVerley-Burton M. 1995: A phylogenetic analysis and revised classification of the Monocotylidae Taschenberg, 1879 (Monogenea). Syst. Parasitol. 32: 159-191.

De Carvalho M.R., Lovejoy N., Rosa R.S. 2003: Potamotrygonidae (River stingrays). In: R.S. Reis, S.O. Kullander and J.R. Ferraris (Eds.), Checklist of the Freshwater Fishes of South and Central America. EDIPUCRS, Porto Alegre, Brazil, pp. 22-28.

DESDEVISES Y. 2001: The phylogenetic position of Furnestinia echeneis (Monogenea, Diplectanidae) based on molecular data: a case of morphological adaptation? Int. J. Parasitol. 31: 205-208.

Domingues M.V., MARQUeS F.P.L. 2007: Revision of Potamotrygonocotyle Mayes, Brooks \& Thorson, 1981 (Platyhelminthes: Monogenoidea: Monocotylidae) with descriptions of four new species from the gills of freshwater stingrays, $\mathrm{Po}$ tamotrygon spp. (Rajiformes: Potamotrygonidae) from the $\mathrm{La}$ Plata river basin. Syst. Parasitol. 67: 157-174.

Goulding M., CARVAlho M.L., FERREIRA E.G. 1988: Negro River: Rich Life in Poor Water: Amazonian Diversity and Food Chain Ecology as Seen Through Fish Communities. SPB Academic Publishing, The Hague, 200 pp.

HuBERT N., RENNO J.-F. 2006: Historical biogeography of South American freshwater fishes. J. Biogeogr. 33: 1414-1436.

Humason G.L. 1979: Animal Tissue Techniques. 4th ed. W.H. Freeman and Company, San Francisco, $661 \mathrm{pp}$.

KRITSKY D.C., BOEGER W.A. 2002: Neotropical Monogenoidea. 41. New and previously described species of Dactylogyridae (Platyhelminthes) from the gills of marine and freshwater perciform fishes (Teleostei) with proposal of a new genus and a hypothesis on phylogeny. Zoosystema 24: 7-40.

KRITSKY D.C., BOEGER W.A., JÉGU M. 1996: Neotropical Monogenoidea. 28. Ancyrocephalinae (Dactylogyridae) of piranha and their relatives (Teleostei, Serrasalmidae) from Brazil and French Guiana: species of Notozothecium Boeger and Kritsky, 1988, and Mymarothecium gen. n. Proc. Helminthol. Soc. Wash. 63: 153-175.

KRITSKY D.C., BOEGER W.A., JÉGU M. 1997: Neotropical Monogenoidea. 29. Ancyrocephalinae (Dactylogyridae) of piranha and their relatives (Teleostei, Serrasalmidae) from Brazil: species of Amphithecium Boeger and Kritsky, 1988, Hetero-
Acknowledgements. We would like to thank M.L. Goés, S. Melo and N. Luchetti for assistance during the collecting trip to the Negro River; V.M. Bueno (Universidade de São Paulo, Brazil) and F. Reyda (Connecticut University, USA) reviewed early versions of the manuscript. We thank the Museu de Zoologia da Universidade de São Paulo (MZUSP) and Instituto de Biociências (USP) for scanning electron microscopy support. E. Hoberg and P. Pilitt (USNPC) and S. Gardner and F.A. Jiménez-Ruiz (HWML) allowed access to specimens under their curatorship. This work was supported by a research grant from the Fundação de Amparo à Pesquisa do Estado de São Paulo - FAPESP (FAPESP 03/01816-2 and 05/01299-3) to FPLM and by the post doctoral fellowship to MVD (FAPESP 04/09267-0).

thecium gen. n. and Pithanothecium gen. n. Proc. Helminthol. Soc. Wash. 64: 25-54.

KRITSKY D.C., BOEGER W.A., JÉGU M. 1998: Neotropical Monogenoidea. 31. Ancyrocephalinae (Dactylogyridae) of piranha and their relatives (Teleostei, Serrasalmidae) from Brazil: species of Notothecium Boeger and Kritsky, 1988, and Enallothecium gen. n. Proc. Helminthol. Soc. Wash. 65: 31-49.

Lovejoy N.R., Albert J.S., CRAMPton W.G.R. 2006: Miocene marine incursions and marine/freshwater transitions: evidence from Neotropical fishes. J. S. Am. Earth Sci. 21: 5-13.

Lovejoy N.R., Bermingham E., Martin A.P. 1998: Marine incursion into South America. Nature 396: 421-422.

MARQUES F.P.L. 2000: Evolution of Neotropical freshwater stingrays and their parasites: taking into account space and time. Unpublished Ph.D. dissertation. University of Toronto, Ontario, Canada, 325 pp.

MAyes M.A., Brooks D.R., ThORson T.B. 1981: Potamotrygonocotyle tsalickisi, new genus and species (Monogenea: Monocotylidae) and Paraheteronchocotyle amazonensis, new genus and species (Monogenea: Hexabothriidae) from Potamotrygon circularis Garman (Chondrichthyes: Potamotrygonidae) in northwestern Brazil. Proc. Biol. Soc. Wash. 94: 1205-1210.

Mizelle J.D., KLUCKA A.R. 1953: Studies on monogenetic trematodes. XIV. Dactylogyridae from Wisconsin fishes. Am. Midl. Nat. 49: 720-733.

Mo T.A. 1991: Variation of opisthaptor hard parts of Gyrodactylus salaris Malmberg, 1957 (Monogenea: Gyrodactylidae) on parr of Atlantic Salmon Salmo salar L. in laboratory experiments. Syst. Parasitol. 20: 11-19.

PERERA K.M.L. 1992: The effect of host size on large hamuli length of Kuhnia scombri (Monogenea: Polyopisthocotylea) from Eden, New South Wales, Australia. Int. J. Parasitol. 22: $123-124$.

ROHDE K. 1991: Size differences in hamuli of Kuhnia scombri (Monogenea: Polyopisthocotylea) from different geographical areas not due to differences in host size. Int. J. Parasitol. 21: $113-114$

SURIANO D.M. 1985: El genero Unilatus Mizelle \& Kritsky, 1967 (Monogenea: Ancyrocephalidae) parasito de Siluriformes (Pisces: Loricariidae) del Negro River. Manaus, Brazil. Neotropica 31: 163-175.

THONEY D.A. 1988: Developmental variation of Heteraxinoides xanthophilis (Monogenea) on hosts of different sizes. J. Parasitol. 74: 999-1003.

VAN EVERY L.R., KRITSKY D.C. 1992: Neotropical Monogenoidea. 18. Anacanthorus Mizelle and Price, 1965 (Dactylogyridae, Anacanthorinae) of piranha (Characoidea, Serrasalmidae) from the Central Amazon, their phylogeny, and aspects of host-parasite coevolution. Proc. Helminthol. Soc. Wash. 59: 52-75. 